\title{
The Relationship between Money, Government Spending and Inflation in the Iranian Economy
}

\author{
Mohsen Mehrara ${ }^{1}$, Ahmad Sujoudi ${ }^{2}$ \\ ${ }^{1}$ Faculty of Economics, University of Tehran, Tehran, Iran \\ ${ }^{2} \mathrm{PhD}$ student, Islamic Azad University Isfahan (Khorasgan) Branch \\ *E-mail address: mmehrara@ut.ac.ir, sujudi89@yahoo.com
}

Keywords: Bayesian econometrics; inflation; money supply; government spending; the economy of Iran

\begin{abstract}
Inflation is one of the important macroeconomic variables that has a close relationship with many of the real and monetary variables and has unfavorable effects such as loss of productivity, reduction of economic growth, and rise of economic inequality. Therefore, the reduction of inflation has always been the most important economic objective of policy makers. The main objective of this study is to examine the relationship between, inflation, money supply and government spending in Iran during the period 1959- 2010. To that end, Bayesian econometric approach was used. The results of the Bayesian Model averaging method imply that the growth rate of money, economic growth rate, inflation rate, the logarithm of the ratio of liquidity to GDP, and growth in energy prices had a significant positive significant effect on inflation. Among these 3 variables, growth rate of money has the highest impact on inflation. The results showed that the growth rate of government spending, GDP growth rate and the exchange rate had no significant effect on the inflation. Therefore, the study recommends controlling the inflation through decline in liquidity growth rate, and energy prices.
\end{abstract}

\section{INTRODUCTION}

According to the literature, inflation is a continuous process of rise of the general level of prices which can also be called a continuous reduction of the value of money. Also theoretically, shortterm inflation can be caused by demand and supply pressure. Demand pressures arising from expansionary fiscal policy (government spending and tax cuts) or expansionary monetary policy (increasing the money supply) or a reduction of demand for money. Supply pressure happens due to the capital reduction, supply reduction and demand for labor and reduction of other inputs. In both cases the price level will rise and would cause inflation. But what should be considered in this context is that none of the supply-side factors and sources of inflation and expansionary fiscal policy cannot cause inflation. And a sustained increase in the general level of prices in the long run can only be created by the continuous growth of money supply (Romer and Romer, 1989: 743-735). Existence of adverse effects of inflation on the economy has caused policy makers to give priority to inflation control in the economic plannings. One of the important questions in the discussion of economic stabilization policy is what tools should be used to fight inflation. According to many economists, the answer must be sought in monetary policy of states (Yashioka, 2002)).

Accordingly, anti-inflationary policies can have four potential effects: recession effects, capital stock effect, improved allocation effect, and productivity growth effect. Inflation has an adversely affect the output and it is believed that the anti-inflationary policy of temporary negative effect on production. Also, inflation is a temporary reduction in investment spending and, therefore, reduces the accumulation of capital. But this will be a constant effect. Anti-inflationary policies resulted in improved resource allocation and, thus, improve the production and the effect is permanent. But inflationary policies could have a positive effect on productivity growth because of innovations (Samadi et al., 2006). 
In the Iranian economy because of economic conditions, including structural problems, the economy's dependence on oil revenues, successive changes in the monetary authorities and the subsequent changes in the monetary policy of the country, and chronic and persistent deficits the inflation has been dominant and has led the authorities to give priorities to controlling inflation in the economy. In this context, understanding the roots of inflation can assist authorities in designing proper policies. The main objective of this study was to examine the relationship between money supply, inflation and government spending in the Iranian economy during the period 1959 to 2010.

Literature review

Andersson et al (2009) in a comprehensive report examines the determinants of inflation and the general level of prices in Europe. For this purpose, the dynamic panel techniques used during the period 1999-2006 and have concluded that differences in inflation and its persistence in different countries depend on the way of managing the general level of price and also market regulations. Bashir et al (2011) in an article using time series data for the period 2010-1972 from Pakistan and econometric techniques including cointegration and vector error correction studies inflation in Pakistan. They have concluded that the most important variables affecting inflation are output, money supply growth, government spending, and the import price index.

Seymur (2011) in his study of the determinants of inflation in 10 countries over the 20081996 period concludes that the growth rate of wages and exchange rate do not cause inflation, but the main reason for the inflation is money growth. Aurangzeb and Anwar U1 Haq (2012) study the Pakistani economy using time series data for the period 2010-1981 to find the determinants of inflation in Pakistan. They came to the conclusion that GDP has a significant negative impact on inflation; however, exchange rates, interest rates, budget deficit and unemployment rate have a positive and significant effect on inflation in Pakistan.

Azizi (2006) in an article discussed the relationship between budget deficits, inflation and money growth. The main objective of this paper was to examine the theoretical and experimental relationship between fiscal deficits and inflation over the period 1975-2004. He believes that the statistical evidence of the empirical research on the relationship between inflation and ratio of budget deficit to output show the relationship between budget deficit and inflation are not the same for different countries. The results show that the relationship between inflation and budget deficit are not statistically significant. Mostafavi (2007) in a paper examines the causal relationship between inflation and money in Iran. For this purpose, a method of Granger causality in inflation and Johansen's weak exogeneity test is used. As a result, short-term money could have an impact on inflation, but it was not a long term effect. Furthermore, monetary policy has been effective in the short term, while in the long-term monetary policy was ineffective in practice.

In this paper we want to test the following two hypotheses:

- Money has a positive and significant effect on inflation.

- Real government spending has a positive and significant effect on inflation.

\section{METHODOLOGY}

We employ data over the period 1959-2010. In this connection all the time series data are obtained from the Central Bank of Iran. To analyze the data a Bayesian econometric model was used. First, econometric model of inflation based on the theoretical and experimental studies was obtained (Table 1). In this table $d$ indicates the first difference and L represents the logarithm of the variable. In this study, because of the high number of models and explanatory variables that have been confirmed in previous studies, Bayesian Model Averaging (BMA) method which allows much more regressors in the inflation equation than the conventional approach based on OLS method. However, due to the limited number of observations, we considers just important variables that influence the inflation. Then the extent and probability of the impact of these variables on the inflation are estimated. In this regard, the softwares like Eviews, Office and Stata were used. 
Table 1: Variables Econometric Model

\begin{tabular}{|c|c|c|}
\hline & Dependent variable & \\
\hline $\begin{array}{l}\text { Variable } \\
\text { name }\end{array}$ & Definition & \\
\hline \multirow[t]{2}{*}{ dlpgdp } & Inflation & Inflation rate \\
\hline & Explanatory variables & \\
\hline $\begin{array}{l}\text { Variable } \\
\text { name }\end{array}$ & Definition & $\begin{array}{l}\text { The expected } \\
\text { sign }\end{array}$ \\
\hline dlpgdp1 & Lagged Inflation Rate & Positive \\
\hline $\mathrm{d} \operatorname{lm} 2 \mathrm{j}$ & Liquidity growth rate & Positive \\
\hline $\mathrm{dlm}$ & Money growth rate & Positive \\
\hline $\mathrm{dlg}$ & The growth rate of government spending & Positive \\
\hline dlrgdp & Economic growth & Positive \\
\hline dler & Growth rate of market exchange rate & Positive \\
\hline dlw & The growth rate of wages & Positive \\
\hline dlpe & The growth rate of energy prices & Positive \\
\hline Lm2gdp & Log excess money supply to GDP ratio & Positive \\
\hline
\end{tabular}

\section{FINDINGS}

Using the 9 above mentioned variables, we do the long run BMA analysis. We use 11000 iterations (irep $=11000)$, and we use 1000 (nburn $=1000)$ of them to balance the selection of parameters and maximize the posterior probability function. The remaining 10,000 (nkeep $=10000$ ) BMA final sample are used to estimate the weighted average of the coefficients of the parameters. Using these information, we derive nine optimum models. Table 2 shows the optimum models based on BMA approach that had the highest log of marginal likelihood.

Table 2: Different models of optimal long-term

\begin{tabular}{|c|c|c|c|c|c|c|c|c|c|}
\hline Model & $(1)$ & $(2)$ & $(3)$ & $(4)$ & $(5)$ & $(6)$ & $(7)$ & $(8)$ & (9) \\
\hline Variable & 0 & 1 & 1 & 1 & 1 & 1 & 1 & 1 & 1 \\
\hline Dlm2j & 0 & 1 & 1 & 1 & 1 & 1 & 1 & 1 & 1 \\
\hline dlpe & 0 & 0 & 1 & 1 & 1 & 1 & 1 & 1 & 1 \\
\hline Lm2gdp & 0 & 0 & 0 & 0 & 1 & 1 & 1 & 1 & 1 \\
\hline dler & 0 & 0 & 0 & 1 & 1 & 1 & 1 & 1 & 1 \\
\hline dlw & 0 & 0 & 0 & 0 & 0 & 1 & 1 & 1 & 1 \\
\hline dlm & 0 & 0 & 0 & 0 & 0 & 0 & 1 & 1 & 1 \\
\hline dlrgdp & 1 & 0 & 0 & 0 & 0 & 0 & 0 & 1 & 1 \\
\hline Dlpgdp1 & 0 & 0 & 0 & 0 & 0 & 0 & 0 & 0 & 1 \\
\hline dlg & & & & &
\end{tabular}

Table 4 represent the weighted average of the coefficients, the mean and standard deviation of each of the coefficients and the probability that each variable include in model. 
Table 4: Estimation Results

\begin{tabular}{|l|l|l|l|}
\hline $\begin{array}{l}\text { Explanatory } \\
\text { Variables }\end{array}$ & $\begin{array}{l}\text { Probability of } \\
\text { Inclusion }\end{array}$ & $\begin{array}{l}\text { Standard Error of } \\
\text { Posterior Coefficients }\end{array}$ & $\begin{array}{l}\text { Mean of Posterior } \\
\text { Coefficients }\end{array}$ \\
\hline dlm2j & 1.00 & 0.158 & 0.736 \\
\hline Dlpe & 0.94 & 0.115 & 0.276 \\
\hline Lm2gdp & 0.66 & 0.047 & 0.053 \\
\hline Dler & 0.34 & 0.104 & 0.603 \\
\hline Dlw & 0.26 & 0.104 & -0.0487 \\
\hline Dlm & 0.12 & 0.026 & 0.043 \\
\hline Dlrgdp & 0.13 & 0.090 & -0.018 \\
\hline dlpgdp1 & 0.13 & 0.066 & 0.097 \\
\hline Dlg & 0.13 & 0.055 & -0.005 \\
\hline
\end{tabular}

According to the results in Table 4, the average mean of the coefficients for each variable influencing inflation is calculated. In other words, based on the 10,000 estimations, average effect of each covariate on the inflation rate is calculated. Table 4 also shows that the probability of inclusion of each explanatory variables in the regression. So, as previously mentioned, in the conventional regression models, the results are not robust and they change when we add or delete an explanatory variable. But based on Bayesian method, the results are robust and these models can show the probability of variables on one hand and the posterior coefficients on the other hand. Therefore, the results are more reliable. As the results in Table 4 show, among the 9 explanatory variables considered in all models, the growth rate of liquidity, as expected, was significant in all models and its impact on the inflation was about 0.74 . This result implies that one percentage increase in the growth rate of the money supply, inflation increase was about 0.74 percentages. The macroeconomic literature on the relationship between inflation and money growth implies the relationship between money and inflation is a monetary phenomenon, and this relationship is one to one. Although in this study the relationship between inflation and money growth is not one; however, we found a significant positive correlation between the two.

According to the results, the growth rate of energy prices is one of the most important explanatory variables that affect inflation. The results show that the probability of inclusion of this variable in model is $94 \%$. Moreover this variable is statistically significant. Influence of this variable on the average inflation rate is equal to 0.27 . The coefficient implies that an increase in the price of energy is one of the most important factors affecting inflation in Iran during the period studied and the results show that every one percent increase in the rate of growth in energy prices causes inflation rate to increase about 0.27 percent. This result is in accordance with theoretical expectations. Because the increase in the price of energy increases production costs, leading to reduced and hence the supply curve shifts to the left. Therefore, in the framework of macroeconomic analysis of supply and demand, shift to the left of the aggregate supply curve reduces the output and rises the price level or inflation.

The third important factor affecting the rate of inflation is the ratio of liquidity to GDP. The results show that the relationship between this variable and the inflation rate is positive but nonsignificant. Therefore, based on the results, in $66 \%$ of the estimated regression coefficient for this variable was significant and its impact on the average rate of inflation is about 0.05 . This ratio means that for every 10 percent increase in liquidity ratio to GDP, inflation increases on average half a percent. Because, according to the literature on macroeconomics, money growth should be commensurate with the growth rate of the economy, and most of it is due to inflation. It is known that if the base money growth rate be higher than the rate of economic growth, it will lead to inflation. Precisely this view is consistent with experimental findings. Although its significance level is low.

Because the likelihood of repeated estimates of the impacts of government spending is less than 0.5 , we can say that it has no significant effect on inflation in the country. Therefore, the 
hypothesis that the government expenditures has a positive effect on inflation can be rejected. The results show the growth rate of government spending as a key explanatory variable, was significant only in $13 \%$ of the regressions. The average estimated coefficients for the variables in the regression models was estimated -0.005 . In other words, changing government spending (as a representative of the government's fiscal policy) in Iran during the past 50 years has had a negative impact on inflation; however, this effect was not statistically significant. The negative effect of government spending on inflation needs to be analyzed in details in terms of the portion of government spending on infrastructure, education, health insurance or transportation. In Iran, some part of the government spending is devoted to subsidies goods and services, which causes an increase in supply. It is worth noting that the impact of government spending on inflation is very low and it is negligible. The effect was not statistically significant and therefore can be argued that the long-term fiscal policies implemented by the government through government spending has no effect on inflation and it is neutralized.

\section{CONCLUSION}

The following includes a summary of the findings:

- Results of the optimization model, implies that only three of the 9 major explanatory variables, namely, the growth rate of liquidity, energy prices, and the ratio of money supply to GDP have positive and significant impacts on inflation and all other variables had no significant effect on inflation. Among these three variables, the growth rate of money supply, with the posterior probability $(100 \%)$, has the largest impact on the inflation rate and the growth rate of energy prices comes in the second. The results show that the growth rate of government spending, growth rate of GDP, and the exchange rate had no significant effect on the rate of inflation.

- The hypotheses regarding the existence of a positive relationship between liquidity and inflation in Iran is cannot be rejected. Based on the results from the Bayesian models the average effect of the growth rate of liquidity on inflation is about 0.74 , and it is statistically significant in all the estimated models. Therefore, it is considered as one of the most important variables influencing the inflation in Iran.

- The second hypothesis about the positive relationship between government spending and inflation in Iran was rejected. In fact, the results indicate that the government spending (as a representative of the government's fiscal policy) in Iran during the past 50 years has had a negative but insignificant impact on inflation. The reason for this negative effect, might be the high share of subsidies paid by government to goods and services, which had decreased the production cost and shifted the aggregate supply curve to the right. And therefore it can be argued that the long-term effects of fiscal policies on inflation have been null.

\section{References}

[1] Samadi, AS. E. Haghighat AS. Amin Zadeh K. (2006), inflation, productivity and structural failure, empirical evidence of the economy from 1959 to 2001, Journal of Economic Research, No. 27, Summer, pp. 65-87.

[2] Azizi F. (2006), deficits and inflation in Iran, 1975-2004, Economic Essays Autumn and winter, 2006, 3 (6): 189-214.

[3] Mostafavi, M. (2007) investigates the causal relationship between money and inflation in Iran, Journal of Quantitative Economics, Journal of Economic Studies; 3(14): 3-17

[4] Agayev Seymur (2011), "Exchange Rate, Wages, and Money; What Explains Inflation in CIS Countries", EuroJournals Publishing",Vol.1, 6-13.

[5] Andersson M., Masuch K. and Schiffbauer M. (2009), "determinants of inflation and price level differentials across the Euro area countries", Working paper series, no. 1129/ December. 
[6] Aurangzeb and Anwar U1 Haq (2012), "Determinants of Inflation in Pakistan", Universal Journal of Management and Social Sciences, vol. 2, no.4; 23-40.

[7] Bashir Furrukhand et al.(2011), "determinants of inflation in Pakistan: aneconometric analysis using Johanson cointegration approach", Australian Journal of Business and Management Research,1(5). pp.71-82

[8] Romer, C. and Romer, D. (1989), "Does Monetary Policy Matter? A New Test in the Spirit of Friedman and Schwartz", NBER Chapters, in: NBER Macroeconomics Annual 1989, Volume 4, pages 121-184 National Bureau of Economic Research, Inc.

[9] Yashioka S. (2002), "Estimation of output gap in southeast Asian countries, state space model approach", Tsd Discussion Paper, no.2. 